\title{
COMMUNICATION
}

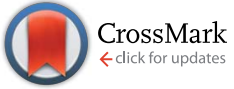

Cite this: RSC Adv., 2016, 6, 68638

Received 25th May 2016 Accepted 13th July 2016

DOI: 10.1039/c6ra13564a

www.rsc.org/advances

\section{Osteometrics in burned human skeletal remains by neutron and optical vibrational spectroscopy}

\author{
M. P. M. Marques, ${ }^{\star a b}$ D. Gonçalves, ${ }^{\text {cde }}$ A. I. C. Amarante, ${ }^{\text {ab }}$ C. I. Makhoul, ${ }^{\text {ad }}$ S. F. Parker ${ }^{f}$
} and L. A. E. Batista de Carvalho ${ }^{a}$
Vibrational spectroscopic techniques are applied to the osteometric study of burned human skeletal remains. This is an innovative way of tackling heat-induced changes in human bone tissue, aimed at relating burned to pre-burned parameters which will have a significant impact in forensic, bioanthropological and archaeological contexts.

\section{Introduction}

Frequently, the skeleton constitutes the only preserved human remains found in archaeological and forensic settings, and it is not unusual to find that the body has, deliberately or not, been subjected to heat (e.g. through cremation, aircraft accidents, bush fires or explosions). ${ }^{1}$ The examination of unburned skeletal remains is routinely carried out by either bioarchaeologists or forensic scientists to retrieve information such as the biological profile or the positive identification of the deceased, as well as the circumstances of death. Unfortunately, the analysis of bones affected by high temperatures encounters serious problems, as heat induces significant changes in the skeleton, ${ }^{2,3}$ which interfere with the reliability of the available methods. ${ }^{2}$ Indeed, the metric techniques commonly used for human identification from burned remains are conceived for unmodified dimensions, while burning at high temperatures leads to considerable variations in the size of bones which can, apparently randomly, either decrease or increase., ${ }^{4,5}$ This severely interferes with the precision of the estimation, which is based on references from unburned skeletons with ante mortem records. Consequently, the analysis of burned human bones carries a significant degree of uncertainty and does not lead to

a"Molecular Physical Chemistry" R\&D Unit, Department of Chemistry, University of Coimbra, Coimbra, Portugal.E-mail:pmc@ci.uc.pt

${ }^{b}$ Department of Life Sciences, University of Coimbra, Coimbra, Portugal

${ }^{c}$ Research Centre for Anthropology and Health (CIAS), Univ. Coimbra, Portugal

${ }^{d}$ Laboratory of Forensic Anthropology, Centre of Functional Ecology, University of Coimbra, Coimbra, Portugal

${ }^{e}$ Archaeosciences Laboratory, Directorate General Cultural Heritage, LARC/CIBIO/ InBIO, Portugal

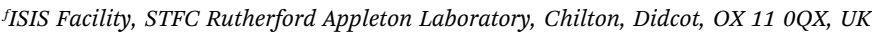

reliable inferences. The goal of this pilot spectroscopic study is to assess whether this randomness is real or, on the contrary, if heat-induced dimensional changes are predictable and quantifiable. In this case, a relationship between the dimensions of burned and unburned bones may be established, allowing to reliably profile human skeletal remains even after being subjected to burning events. The ability to accurately estimate heatprompted changes in bone will have an immediate and invaluable impact on forensic investigations ${ }^{6}$ and archaeological research.?

Although previous studies have attempted to tackle this problem, ${ }^{5,8}$ this is the first time that an experimental approach based on the intrinsic properties of bone (e.g. microcrystallinity features) has been undertaken, and it is, to the best of the authors' knowledge, the first reported inelastic neutron scattering (INS) work on human burned bones. Bone is a heterogeneous material comprising a protein component (largely type I collagen) woven into an inorganic matrix of hydroxyapatite of approximate formula $\mathrm{Ca}_{10}\left(\mathrm{PO}_{4}\right)_{6}(\mathrm{OH})_{x}$ partly substituted by carbonate ( $\mathrm{ca} .7 \mathrm{wt} \%$ ) at both hydroxyl (A-type) and phosphate (B-type) sites, ${ }^{9,10}$ which accounts for $70-80 \mathrm{wt} \%$. The degree of hydroxylation of mature bone apatite, however, is still controversial, some authors claiming that it may be very low or even inexistent, ${ }^{11-14}$ contrary to the general belief in the biomaterials and medical community. Nevertheless, inelastic neutron scattering experiments such as the present one provide spectroscopic proof of the occurrence of hydroxyl groups in the bone's inorganic component ${ }^{9,15}$ (particularly upon heating) and are expected to contribute to the elucidation of this matter.

Upon diagenesis (a set of post-mortem processes leading to physical and chemical alterations) bone undergoes several modifications in molecular structure. The main premise of this work is that the corresponding measured macroscopic dimensional changes (obtained concomitantly with the spectroscopic work) are primarily due to variations in the crystal structure of bioapatite. Heating, in particular, is known to lead to an increased crystallite size and decreased lattice strain (i.e. higher organisation) within the bone's inorganic matrix, rendering the 
apatite structure more accommodating to substitutions. ${ }^{\mathbf{1 4}}$ These changes are reflected in the crystallinity index (CI) and carbonate/phosphate $\left(\mathrm{CO}_{3} / \mathrm{P}\right)$ ratio of the analysed samples, ${ }^{2,16-18}$ which can thus be used to determine the conditions of the burning process (such as maximum temperature and duration). The fact that these modifications in the elemental structure of bone's apatite are clearly reflected in its vibrational spectra fully justifies the use of these techniques (Raman, ${ }^{19,20}$ Fourier-transform infrared (FTIR) $)^{17,21-23}$ and inelastic neutron scattering (INS) spectroscopies, ${ }^{9,24}$ ) to monitor heat-induced bone diagenesis. A correlation is sought between the pre-burning bone dimensions and the experimental set of data obtained for the burned sample: heatinduced macroscopic dimensional changes, crystal microstructure, and $\mathrm{CI}$ and $\mathrm{CO}_{3} / \mathrm{P}$ values (as well as other relevant relationships obtained from the spectroscopic data).

\section{Experimental}

In the present study, samples were collected from bones of three experimentally burned human skeletons, that are part of the $21^{\text {st }}$ century collection of identified human skeletons of the Laboratory of Forensic Anthropology of the University of Coimbra (Portugal). ${ }^{25}$ This is a unique collection of experimentally burned human skeletons, that allowed us unmatched access to samples for the reported work. The analysis was focussed on two distinct bones that are osteometrically very informative (e.g. regarding individual biological profiles): femur and humerus. The burning process was carried out (in an electric muffle furnace) under controlled laboratory conditions regarding the intensity and duration: 500, 700 and $900{ }^{\circ} \mathrm{C}(\mathrm{a}$ range where considerable heat-induced osseous changes are likely to occur), at a heating rate of $c a \cdot 6-10{ }^{\circ} \mathrm{C} \mathrm{min}^{-1}$, for a period of 120 minutes. For comparison purposes, data (both spectroscopic and metric) was also acquired for bones from the same sources prior to burning, as well as for unburned bones subject to defatting, deproteination and dehydration by reported methods. ${ }^{9}$ INS (MAPS spectrometer of the ISIS Pulsed Neutron Source, STFC Rutherford Appleton Laboratory, UK) and Raman data (Horiba Jobin-Yvon T64000 spectrometer coupled to a $514.5 \mathrm{~nm} \mathrm{Ar}^{+}$laser line, "Molecular PhysicalChemistry", University of Coimbra (QFM-UC), Portugal) were measured for grinded bone samples (mesh size of $400 \mu \mathrm{m}$ ), while $\mathrm{KBr}$ pellets were used for FTIR data collection (Bruker Optics Vertex 70 FTIR spectrometer, QFM-UC). In addition, a reference spectrum of hydroxyapatite was measured: highly crystalline SRM 2910b calcium hydroxyapatite $\left(\mathrm{Ca}_{10}\left(\mathrm{PO}_{4}\right)_{6}\right.$ $\left.(\mathrm{OH})_{2}, \mathrm{Ca} / \mathrm{P}=1.67\right)$ from NIST, Gaithersburg/MA (USA). ${ }^{26}$ The neutron data was reduced into energy transfer spectra using the MANTID program (version 3.4.0 (ref. 27)).

\section{Results and discussion}

The combined application of the optical and neutron spectroscopic techniques allowed access to the whole vibrational profile of the burned human bone samples, which were fully assigned (Fig. 1): (i) the bands ascribed to the phosphate
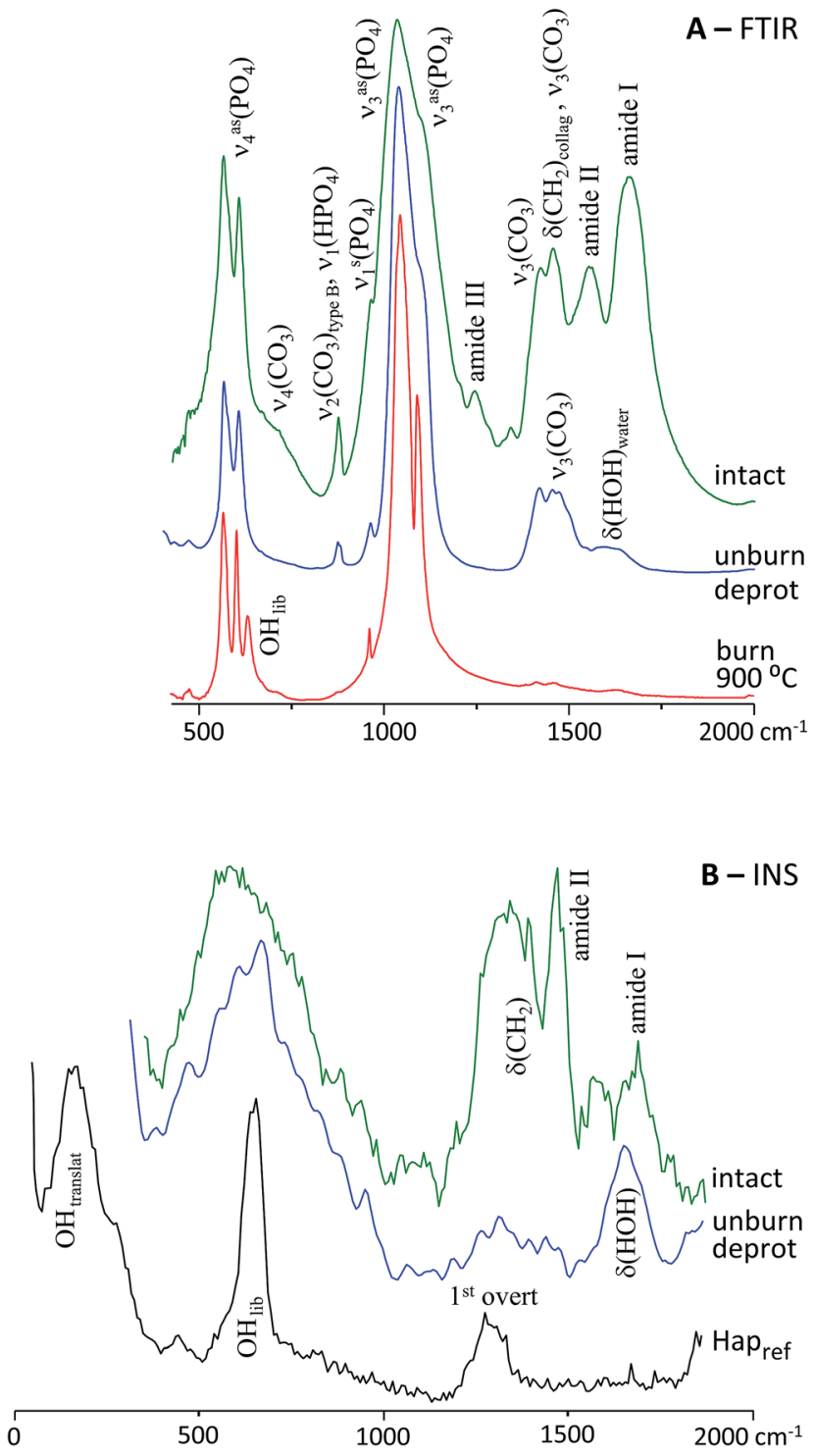

Fig. 1 FTIR (A) and INS (B) spectra of human femur: intact; unburned defatted/deproteinated; burned at $900{ }^{\circ} \mathrm{C}$. The INS spectrum of reference calcium hydroxyapatite (HAp, SMR2910b) is also shown, for comparison (INS spectra were recorded with $2024 \mathrm{~cm}^{-1}$ (HAp) and $5240 \mathrm{~cm}^{-1}$ incident energy).

tetrahedra $\left(\mathrm{PO}_{4}{ }^{3-}\right)$ and the planar carbonate ion $\left(\mathrm{CO}_{3}{ }^{2-}\right)$, clearly detected by Raman and FTIR and allowing the determination of several spectroscopic parameters indicative of chemical composition (e.g. CI and $\mathrm{CO}_{3} / \mathrm{P}$ values); ${ }^{\mathbf{1 7} 21}$ (ii) the signals due to the bone's organic constituents (e.g. collagen amide bands and $\mathrm{CH}_{2}$ deformations from lipids and proteins); (iii) the main signals from bioapatite, some of which can only be accessed by neutron spectroscopy - at 647, 1302, 1941, 2560, 3590 and 4246 $\mathrm{cm}^{-1}$, respectively ascribed to the $\mathrm{OH}$ librational mode, its first, second and third overtones, the $\mathrm{OH}$ stretching vibration and the $\left(\mathrm{OH}_{\text {lib }}+\nu(\mathrm{OH})\right)$ combination band (Fig. 2). $\mathrm{OH}_{\text {lib }}$ and $\nu(\mathrm{OH})$, in particular, are associated with the short-range order and hydrogen-bonding profile within the bioapatite crystalline framework (HAp). 


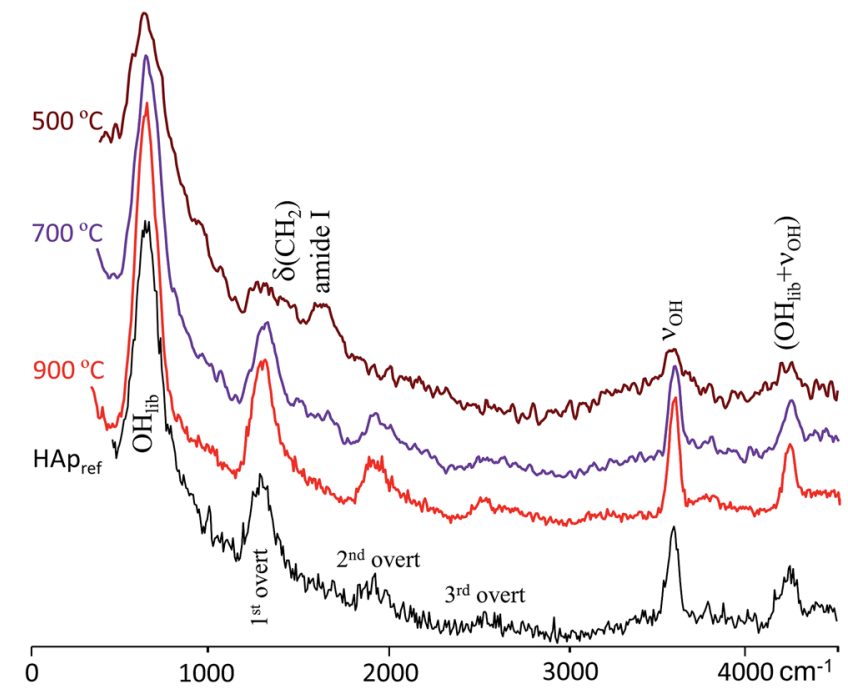

Fig. 2 INS spectra (with $5240 \mathrm{~cm}^{-1}$ incident energy) of $\mathrm{HAp}$ (SMR2910b) and human femur burned at 500, 700 and $900{ }^{\circ} \mathrm{C}$.

For the samples subjected to the highest temperature tested $\left(900{ }^{\circ} \mathrm{C}\right)$ very good quality spectra were obtained, as they were free from the features due to the bone's organic matrix (lipids, protein and water). This enabled a clear detection of the signals from bioapatite, particularly those ascribed to the $\mathrm{OH}$ libration and stretching. These HAp typical vibrational modes, readily discernable in the INS spectra, were confirmed as suitable spectroscopic biomarkers of heat-induced changes in bone. Actually, heating leads to variations in the elemental composition of bone, such as carbonate loss (decreasing $\mathrm{CO}_{3} / \mathrm{P}$ ), that trigger a significant rearrangement of the apatite's $\mathrm{H}$-bond network leading to marked changes in crystalline structure (increasing CI). ${ }^{28}$ Additionally, the concomitant observation (by INS) of the $\nu(\mathrm{OH})$ fundamental mode and $\left(\mathrm{OH}_{\text {lib }}+\nu(\mathrm{OH})\right)$ combination feature allowed their irrefutable assignment to hydroxyl groups within the bone's inorganic framework (HAp). Furthermore, the INS technique enabled us to accurately monitor the presence of protein, through the detection of its characteristic methyl torsion $\left(\tau\left(\mathrm{CH}_{3}\right)\right)$ as an intense band around $250 \mathrm{~cm}^{-1}$ (not observable by optical vibrational spectroscopy).

For the unburned bones, the spectra were dominated, as expected, by lipids and protein giving rise to signals at $c a$. 1340, 1460 and $2974 \mathrm{~cm}^{-1}\left(\delta\left(\mathrm{CH}_{2}\right)\right.$ and $\nu\left(\mathrm{CH}_{2}\right)$ modes $)$. These were greatly reduced by the defatting/deproteination process (the protein amide bands disappearing completely), unveiling the main signals from the inorganic bone framework, namely the phosphate and carbonate features (Fig. 1(A)) as well as the $\mathrm{OH}$ librational band (Fig. 1(B)), apart from the typical $\delta(\mathrm{HOH})$ and $\nu(\mathrm{OH})$ water signals at 1650 and $3385 \mathrm{~cm}^{-1}$, respectively.

Upon increasing temperatures, the organic constituents of bone (which provide thermal shielding against the heating effects) were progressively damaged and an increase in crystallinity was detected, in accordance with previously reported results. ${ }^{9,17}$ This was clearly revealed by the band narrowing observed from 500 to 700 and $900{ }^{\circ} \mathrm{C}$ for: (i) the FTIR $\nu_{3}\left(\mathrm{PO}_{4}{ }^{3-}\right)$

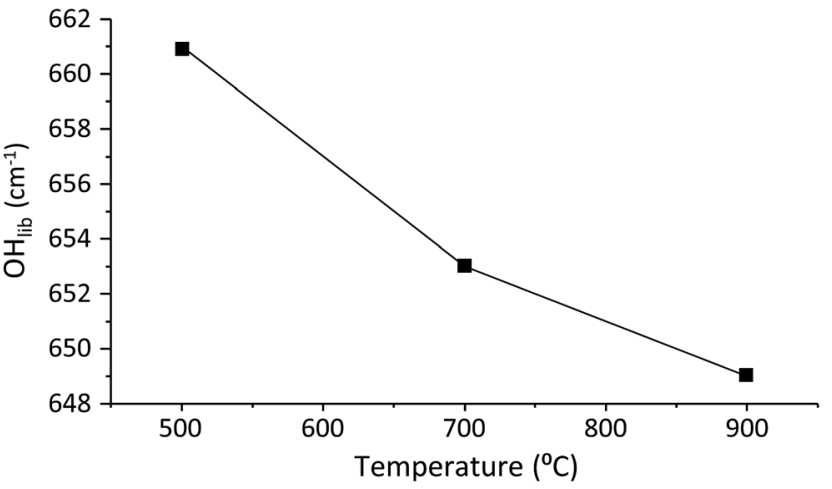

Fig. 3 Variation of the $\mathrm{OH}$ librational frequency with temperature, for human femur subject to burning.

signal centered at $1035 \mathrm{~cm}^{-1}$ (Fig. 1(A)), whose width is related to the amount of carbonate substitution within the apatite lattice; (ii) the INS hydroxyapatite $\mathrm{OH}$ librational band at 647 $\mathrm{cm}^{-1}$ (Fig. 1(B)). Also, at the highest temperature tested $\left(900{ }^{\circ} \mathrm{C}\right)$ crystallinity appears to be maximal, the organic components of bone having been completely destroyed by the burning process (at $T>700{ }^{\circ} \mathrm{C}$ ) and the observed spectral profile being identical to that of the highly crystalline hydroxyapatite reference $\left(\mathrm{Ca}_{10}\left(\mathrm{PO}_{4}\right)_{6}(\mathrm{OH})_{2}\right.$, Fig. 2).

On the contrary, the samples subjected to burning at 500 and $700{ }^{\circ} \mathrm{C}$ were found to retain part of the protein and lipid constituents (e.g. amides I, II and III features at ca. 1665, 1550 and $1242 \mathrm{~cm}^{-1}$ ), the biggest difference arising between 500 and $700{ }^{\circ} \mathrm{C}$, the former still yielding intense bands from the organic components of bone and the latter hardly reflecting their presence (Fig. 1).

A temperature-dependent shift of the bands due to the HAp $\mathrm{OH}$ libration and stretching modes was detected - to high wavenumbers for the former (Fig. 3) and to low frequencies for the latter - which is suggestive of variations in the $\mathrm{H}$-bond pattern within the bone's bioapatite network concurrent with a crystallinity change, ${ }^{17,18}$ that is expected to occur upon exposure to increasing temperatures. Interestingly enough, however, this effect was found not to be identical for both types of bone presently probed (femur and humerus), being larger for femur. This seems to imply that the burning process may not fully overcome the structural differences intrinsic to the bone source (intra-bone variation, i.e. different types or regions of bone), which needs further elucidation.

\section{Conclusions}

This is a pioneer and timely study, reporting an innovative analysis of samples of human bones, both unburned and burned under controlled conditions, through vibrational spectroscopy - both optic (infrared and Raman) and inelastic neutron scattering (INS) - with the aim of understanding and quantifying incremental heat changes in the bone's composition and crystal structure. The spectroscopic results currently reported led to a complete assignment and a thorough 
interpretation of the vibrational profile of human bone, for distinct conditions - unburned (intact), unburned subject to defatting and deproteination, and burned (for distinct temperatures and duration) - as well as for different types of bone (humerus and femur). The good quality INS data obtained for these systems, in particular, allowed us to validate the information retrieved from the Raman and FTIR spectra (e.g. CI and $\mathrm{CO}_{3} / \mathrm{P}$ values), through the observation of vibrational modes only detectable by neutron techniques, shedding light on unsettled issues such as bioapatite hydroxylation and $\mathrm{H}$ bonding pattern within the bone's microcrystalline framework.

The knowledge presently gathered, coupled to the macroscopic information obtained from bone measurements (before and after burning), is expected to lead to a definitive quantitative correlation between the bone's crystalline structure and heat-induced dimensional changes. Once such a relationship is achieved, FTIR should be established as a reliable and straightforward routine technique in osteometric analysis of burned human skeletal remains, linking specific biomarkers of bone heat-induced diagenesis to pre-burned dimensions. Up to this date, in fact, FTIR has only been used to distinguish nonburned bone from low intensity and high-intensity burnings. The current study clearly paves the way for attaining a much more detailed and quantitative discrimination between human bone samples subjected to different burning conditions, according to the exact maximum temperatures and times of exposure to heat. This will have an immediate impact on bioanthropological, archaeological and forensic sciences (e.g. victim's identification in aircraft accidents or acts of terrorism), enabling to extract accurate and reliable information from human skeletal remains, unavailable up to this date.

\section{Acknowledgements}

This work was funded by the Portuguese Foundation for Science and Technology - UID/MULTI/00070/2013, post-doc grant SFRH/BPD/84268/2012 and Project PTDC/IVC-ANT/1201/2014. The STFC Rutherford Appleton Laboratory is thanked for access to neutron beam facilities.

\section{Notes and references}

1 S. Fairgrieve, in Forensic Cremation: Recovery and Analysis, CRC Press, Boca Raton, Florida, 2008.

2 T. J. U. Thompson, Forensic Sci. Int., 2004, 146, S203.

3 S. A. Symes, C. Rainwater, E. Chapman, D. R. Gipson and A. Piper, in The Analysis of Burned Human Remains, ed. C. Schmidt and S. Symes, Academic Press, London, 2008, pp. 15-54.

4 B. Bradtmiller and J. E. Buikstra, J. Archaeol. Sci., 1984, 29, 535.

5 T. J. U. Thompson, J. Archaeol. Sci., 2005, 50, 185.
6 D. H. Ubelaker, Forensic Sci. Int., 2009, 183, 1.

7 L. E. Wright and H. P. Schwarcz, J. Archaeol. Sci., 1996, 23, 933.

$8 \mathrm{~J}$. Buikstra and M. Swegle, in Bone Modification, ed. R. Bonnichsen and M. H. Sorg, Center for the Study of the First Americans, Orono, M.E., 1989, pp. 247-258.

9 M. G. Taylor, S. F. Parker, K. Simkiss and P. C. H. Mitchell, Phys. Chem. Chem. Phys., 2001, 3, 1514.

10 G. Cho, Y. Wu and J. L. Ackerman, Science, 2003, 300, 1123.

11 C. Rey, J. L. Miquel, L. Facchini, A. P. Legrand and M. J. Glimcher, Bone, 1995, 16, 583.

12 T. Nakano, A. Tokumura and Y. Umakoshi, Metall. Mater. Trans. A, 2002, 33, 521.

13 J. D. Pasteris, B. Wopenka, J. J. Freeman, K. Rogers, E. Valsami-Jones, J. A. M. Van der Houwen and M. J. Silva, Biomaterials, 2004, 25, 229.

14 B. Wopenka and J. D. Pasteris, Mater. Sci. Eng., 2005, 25, 131. 15 M. G. Taylor, S. F. Parker and P. C. H. Mitchell, J. Mol. Struct., 2003, 651, 123.

16 C. N. Trueman, K. Privat and J. Field, Palaeogeogr., Palaeoclimatol., Palaeoecol., 2008, 266, 160.

17 T. J. U. Thompson, M. Islam and M. Bonniere, J. Archaeol. Sci., 2013, 40, 416.

18 T. Sui, M. A. Sandholzer, A. J. G. Lunt, N. Baimpas, A. Smith, G. Landini and A. M. Korsunsky, J. R. Soc., Interface, 2014, 11, 20130928.

19 A. Carden and M. D. Morris, J. Biomed. Opt., 2000, 5, 259.

20 C. L. King, N. Tayles and K. C. Gordon, J. Archaeol. Sci., 2011, 38, 2222.

21 T. J. U. Thompson, M. Gauthier and M. Islam, J. Archaeol. Sci., 2009, 36, 910.

22 H. I. Hollund, F. Ariese, R. Fernandes, M. M. E. Jans and H. Kars, Archaeometry, 2013, 55, 507.

23 M. M. Beasley, E. J. Bartelink, L. Taylor and R. M. Miller, J. Archaeol. Sci., 2014, 46, 16.

24 C. K. Loong, C. Rey, L. T. Kuhn, C. Combes, Y. Wu, S. H. Chen and M. J. Glimcher, Bone, 2000, 26, 599.

25 M. T. Ferreira, R. Vicente, D. Navega, D. Gonçalves, F. Curate and E. Cunha, Forensic Sci. Int., 2014, 245, 202.

26 National Institute of Standards and Technology, NIST, http://1.usa.gov/1WcMIO2.

27 O. Arnold, J. C. Bilheux, J. M. Borreguero, A. Buts, S. I. Campbell, M. Doucet, N. Draper, R. Ferraz Leal, M. A. Gigg, V. E. Lynch, L. Chapon, A. Markvardsen, D. J. Mikkelson, R. L. Mikkelson, R. Miller, K. Palmen, P. Parker, T. G. Perring, P. F. Peterson, S. Ren, M. A. Reuter, A. T. Savici, G. Passos, J. W. Taylor, R. Tolchenov, W. Zhou, J. Zikovsky and R. J. Taylor, Forensic Sci. Int., 2014, 764, 156.

28 ISIS experimental report RB1520001/2016, http://www. isis.stfc.ac.uk/. 